\title{
Eqüidade e reforma setorial na América Latina: um debate necessário
}

\author{
Equity and health sector reform in Latin America: \\ a necessary debate
}

Celia Almeida ${ }^{1}$

\footnotetext{
1 Departamento de Administração e Planejamento em Saúde, Escola Nacional de Saúde Pública, Fundação Oswaldo Cruz. Rua Leopoldo Bulhões 1480, Rio de Janeiro, RJ 21041-210, Brasil. calmeida@ensp.fiocruz.br
}

\begin{abstract}
Reform and equity are terms that have frequented political discourse, technical documents, and conceptual discussions in recent decades in different proposals with different ideological references. To understand the importance and centrality of these themes in the contemporary debate in Latin America implies a more in-depth reflection on health policy in the sphere of social policies and to define which reforms were are discussing and the place equity occupies in this discussion. The first part of this essay discusses the concepts of reform and equity, followed by a review of health policy as a social policy. The article ends by discussing the central elements on the health systems reform agenda in Latin America. The conclusion is that the situation is dramatic and that recent reforms have exacerbated inequalities and created new problems by replacing the values of solidarity and equal opportunity with those of "radical utilitarian individualism"; meanwhile, the principle of "health needs" has been replaced by that of "risk", "monetarized" and defined according to the individual's social and economic position. It becomes necessary to resume the discussion of social and health policies as the matrix of principles justifying the order ascribed to any other policies.
\end{abstract}

Key words Equity; Health Sector Reform; Health Policy; Public Policy

Resumo Reforma e eqüidade são termos que têm freqüentado os discursos políticos, documentos técnicos e discussões conceituais nas últimas décadas em distintas propostas com diferentes referenciais ideológicos. Entender a importância e centralidade desses temas no debate contemporâneo na América Latina pressupõe aprofundar a reflexão sobre a política de saúde no âmbito das políticas sociais, qualificar de que reformas estamos falando e o lugar que a eqüidade ocupa nessa discussão. Na primeira parte deste ensaio, discutem-se os conceitos de reforma e eqüidade; a seguir, faz-se um repasse sobre política de saúde como política social; e por fim, são discutidos os elementos centrais da agenda de reforma de sistemas de saúde na região. Conclui-se que a situação é dramática, as reformas recentes exacerbaram as desigualdades e criaram novos problemas, ao substituir valores de solidariedade e igualdade de oportunidade pelos de um "individualismo utilitarista radical"; e o princípio de "necessidades de saúde" pelo de "risco", monetarizado e definido segundo a posição social e econômica do indivíduo. Faz-se necessário retomar a discussão das políticas sociais e de saúde como a matriz de princípios que justificam o ordenamento de quaisquer outras políticas.

Palavras-chave Eqüidade; Reforma do Setor Saúde; Política de Saúde; Política Social 


\section{Introdução}

Reforma e eqüidade são palavras que assiduamente têm freqüentado os discursos políticos, os documentos técnicos e a literatura científica nas últimas décadas. Como recurso de retórica têm servido a distintos espectros ideológicos, adequando-se a diferentes propostas e propósitos. Como conceitos, têm suscitado inúmeras discussões que não logram muito consenso, seja sobre definições, seja sobre operacionalização. Em termos técnicos e metodológicos têm merecido muita atenção dos estudiosos, consultores e pesquisadores, desenvolvendo-se instrumentos de medida e de implementação de políticas pró-eqüidade, que, de novo, alavancam diferentes agendas e projetos políticos.

Isso se verifica seja no âmbito geral das discussões sobre desenvolvimento econômico e social, seja no campo das políticas setoriais. Entre estas últimas, o debate vem sendo pautado pela discussão de novos modelos de reorganização de sistemas de proteção social e pela redefinição de pacotes de benefícios e serviços, revigorando falsos dilemas e velhos confrontos, como público versus privado, Estado versus mercado. Por outro lado, é permeado também pela busca de evidências empíricas e pela constatação das inerentes contraposições que esses processos de reforma setorial têm enfrentado, principalmente entre eficiência, eqüidade e qualidade.

E ainda que a implementação de mudanças, e a própria discussão de políticas de reforma tenham inúmeras especificidades e sejam únicas em cada país, seja no Norte ou no Sul, agendas e argumentos comuns têm sido difundidos e adaptados a distintas realidades, traduzidos em propostas dirigidas à superação de desigualdades.

A que se deve tanta atualidade e versatilidade?

Entender a importância e centralidade desses temas no debate setorial contemporâneo em nossa região pressupõe tanto aprofundar a reflexão sobre a política de saúde no âmbito das políticas sociais, quanto qualificar de que reformas estamos falando e o lugar que a questão da eqüidade ocupa nessa discussão.

A crise econômica e a mudança na perspectiva de desenvolvimento econômico alavancado pelo Estado, pari passu à hegemonia neoliberal das últimas décadas e às exigências dos ajustes macroeconômicos, com pesados condicionantes estabelecidos pelos credores internacionais, aumentaram de forma importante as desigualdades históricas nos países da região latino-americana. Essa dinâmica é concomitante a complicados processos de transição demo- crática. Como resultado, as políticas públicas implementadas, muitas vezes mais radicais que em outras regiões do mundo, foram objeto de intenso debate crítico, que aumentou de forma substantiva o interesse dos bancos e organismos internacionais na "questão social". Definiramse agendas e específicas prescrições de reforma na área social, acopladas aos empréstimos e apoios financeiros necessários para a superação das crises cíclicas e constantes que têm caracterizado a situação regional desde os anos $\mathbf{8 0}$.

Os sistemas de serviços de saúde foram particularmente visados nesse processo de mudanças, e ainda que tenham aumentado de forma importante as publicações sobre o tema, a reflexão analítica ainda é incipiente, se comparada com outras áreas de política social. A tônica central da maioria dessa literatura, pouco avança na reflexão sobre a análise histórica de estruturação dos sistemas de saúde, ou sobre os pressupostos subjacentes a essas reformas contemporâneas, ou ainda sobre o contexto em que operam, e mesmo a natureza da mudança que preconizam, tendo absorvido, de forma bastante acrítica, a agenda de mudança definida desde fora.

O balanço das décadas de 80 e 90 na América Latina é desanimador: crescimento econômico inexistente ou muito modesto e cíclico; concentração de renda cada vez mais intensa e perversa; aumento importante dos níveis de desigualdade, do número de pobres e da exclusão social, com crescentes limitações ao desenvolvimento e à superação dessas condições de pobreza (Almeida, 2002). No que toca aos sistemas de saúde, apesar da diversidade, têm características comuns que ao mesmo tempo que justificam uma perspectiva regional, impõem maior rigor analítico na análise de cada país particular. A heterogeneidade é muito grande e as reformas implementadas tiveram forte inspiração neoliberal. Mesmo assim, a vanguarda privatizadora chilena e a ambiciosa experiência colombiana convivem com a particular reforma brasileira, com o singular sucesso do modelo sanitário socialista cubano e o igualmente exitoso sistema de Costa Rica. Alguns países dedicam somas importantes de recursos financeiros à saúde, sem entretanto conseguir resultados equivalentes, se comparados com alguns países do Norte do mundo ou mesmo com os conterrâneos mais bem sucedidos em âmbito sanitário. Essa rica diversidade regional está merecendo, de fato, maior atenção dos analistas, acadêmicos ou não.

O objetivo deste ensaio é contribuir para essa discussão. Na primeira parte, discutem-se os conceitos de reforma e eqüidade; a seguir, 
faz-se um breve repasse de algumas questões referentes à política de saúde como política social; e por fim, são discutidos os elementos centrais da agenda de reforma de sistemas de serviços de saúde na região.

\section{Reforma e eqüidade: notas conceituais}

A imprecisão conceitual e estratégica que envolve as duas temáticas - reforma setorial e eqüidade - não é nova. Santos já alertou que a falta de clareza conceitual sobre "o que é política social”, tem permitido que se identifique como tal qualquer política que tenha por objeto "problemas sociais”, “independente dos juízos valorativos sobre a ordem social que subscrevem" (Santos, 1998:35). Inclui-se assim nesse rol, qualquer ação assistencialista ou focalizada para "pobres e necessitados", alegando-se superar desigualdades, mesmo que apenas busquem mitigar os graves resultados negativos de outras políticas e nada ofereçam em termos de justiça social. E advoga-se ser essa a melhor forma de superar as enormes desigualdades evidentes na região latino-americana, historicamente acumuladas é verdade, mas dramaticamente exacerbadas nas duas últimas décadas que encerraram "o longo (e intenso) século XX".

Por outro lado, a noção de "desenvolvimento com eqüidade”, que ganha força nas últimas décadas frente ao descalabro mundial do aumento das desigualdades proporcionado pelas políticas neoliberais, também possibilita a construção de consenso entre distintas correntes político-ideológicas, uma vez que não fere a priori os interesses individuais, pois o avanço em direção à superação da iniqüidade pode ser tão lento e gradual que, de fato, a adoção da eqüidade como princípio pode ser completamente inócua ou vazia de significado.

Em relação ao termo reforma, embora tenha uma origem mais definida historicamente, centrada na clássica antítese reformas-revoluções, que caracterizou a antiga (mas sempre renovada) oposição entre diferentes estratégias de mudança social no interior do desenvolvimento do movimento operário, guardou desse legado a essência dessa antítese, isto é, se refere "ao modo através do qual se dá a mudança e não ao resultado" (Bobbio, 2000:579). Reforma e revolução não são conceitos homogêneos, pois como se referem ao problema da mudança social, às suas causas e seus efeitos, podem ser tratados ora como alternativos, ora como complementares e, tradicionalmente, essa antítese é considerada em forma de dilema. Pode-se di- zer que esse dilema foi parcialmente dissolvido ao se dissociarem as duas temáticas no processo de consolidação das sociedades modernas.

$\mathrm{Na}$ realidade, embora o tema reforma-revolução seja dominante e constitutivo do movimento operário mundial desde sua origem, configurando-se também como divisor de águas na estruturação de partidos políticos de esquerda, propensos à conquista do poder numa perspectiva de impulsionar uma mudança específica da sociedade, não nasceu com o movimento operário. Segundo Bobbio, embora a idéia de revolução entendida como transformação radical da sociedade não fosse estranha ao pensamento político tradicional, um marco importante na temática da reforma-revolução, com todas suas articulações, se dá com a Revolução Francesa, no final do século XVIII. Antes, o termo utilizado para designar uma mudança específica e ampla da sociedade era precisamente "reforma", que se referia ao fenômeno da crise religiosa, e conseqüente ruptura de sua unidade, que assolou a Europa, do século XVI em diante, e que representou, juntamente com o desenvolvimento da nova ciência e da técnica, e da formação dos grandes estados nacionais, o nascimento do mundo moderno (Bobbio, 2000).

No século XVIII, considerado a "era das reformas e dos princípios reformistas, o termo reforma já havia perdido seu caráter original de renovação religiosa e assumira o significado, que permaneceu, de mudança política e social ... além de gradual, legal e parcial, que enquanto tal serve para designar uma idéia das tarefas do governante, um modo de exercer o poder e uma concepção geral do progresso histórico, evolutivo e não catastrófico..." (Bobbio, 2000: 586). Essa concepção é antitética à idéia da grande revolução transformadora radical, simbolizada pela revolução Francesa, o primeiro grande movimento histórico interpretado como uma inversão radical da ordem constituída. Portanto, a antítese "reformas ou revolução" nasce com a contraposição entre a era das revoluções e a Revolução Francesa e foi retomado no âmbito do movimento operário, consolidando o perene debate entre reformistas e revolucionários.

Entretanto, com o passar dos séculos, os dois termos foram mudando de significado e, no dizer de Bobbio, se radicalizaram. A era das reformas foi também a era do despotismo esclarecido, da crença no desenvolvimento da ciência aplicada ao estudo das sociedades humanas e do triunfo da razão. O instrumento de controle e de orientação social era a lei e não era necessário o concurso dos súditos, meros beneficiários das mudanças. As reformas esta- 
vam voltadas para a melhora do aparato estatal, eram mais administrativas do que políticas, ou mais políticas do que sociais, cujo objetivo era a correção dos abusos de um poder intocável, com uma conotação mais negativa que positiva. Para os reformistas, a transformação da sociedade seria resultado de uma série ininterrupta de reformas graduais realizadas segundo o princípio de que a mudança quantitativa consiste, afinal, num salto de qualidade, desde que as reformas incidam sobre as modificações das relações de poder, não apenas político, mas também econômico (as chamadas "reformas estruturais”) (Bobbio, 2000).

Já o reformismo do movimento operário visava transformar radicalmente as relações de poder, a partir de reformas arrancadas a qualquer custo pela luta revolucionária. Num primeiro momento não desdenhava o instrumento legal, de onde nasce a legislação social, mas não o considerava suficiente, sendo que a ele contrapunha a negociação, continuamente desenvolvida e renovada entre as próprias organizações e o poder do Estado, na perspectiva de melhora contínua da sociedade, econômica e social. As demandas por mudança se referem assim não tanto à transformação do aparato estatal, mas “à transformação das relações entre Estado e cidadãos, entre o poder estatal e a sua base social. Trata-se, portanto, de um reformismo que não age no interior do Estado e de seus aparatos, mas se move da sociedade em direção ao Estado ... considerando-o apenas como um instrumento da sua satisfação" (Bobbio, 2000: 588-589). Entretanto, como só o Estado pode fazer reformas, desde que controlado por forças transformadoras, leia-se de inspiração socialista, a "ocupação do Estado" é passo crucial para preparar as reformas que levarão à revolução.

A mudança também se deu em relação ao conceito de revolução: segundo os marxistas, a Revolução Francesa conseguira emancipar o cidadão, mas não o homem, que permanecera à sombra da igualdade apenas formal, mantendo-se todas as desigualdades históricas e constitutivas das sociedades capitalistas. Como tal, foi uma revolução parcial e a "revolução proletária teria sido a revolução total ... e definitiva ... levando a humanidade a sair definitivamente do domínio de classe, e enfim de toda forma de organização política" (Bobbio, 2000:589).

Independentemente das oposições com relação ao método, as duas estratégias partem de uma concepção da história entendida como mudança e como progresso, mas subjacente ao reformismo não revolucionário existe uma idéia evolutiva e positivista da história, onde a transformação se dá de forma cumulativa e gradual.
Por trás dos movimentos revolucionários, a concepção progressiva se constrói a partir de uma sucessão de movimentos positivos e negativos, em permanente avanço, seja da realidade objetiva, seja do conhecimento sobre ela, e, portanto, o processo histórico não se dá por sucessivos acréscimos mas por mudanças dialéticas, que contêm em si o germe da dissolução, onde as negações representam a passagem obrigatória para as subseqüentes afirmações (Bobbio, 2000; a partir de Marx e Engels).

Em síntese, os movimentos de reforma visam melhorar e aperfeiçoar, até mesmo de forma radical, mas nunca destruir o ordenamento existente. Em relação ao sistema político, o reformismo não tem dúvidas: a liberdade individual, a democracia e o bem-estar de todos são princípios fundamentais a serem preservados e, sendo assim, defende que a democracia liberal se fortalece e amplia nos processos de reforma. Quanto ao ordenamento econômico capitalista, porém, a posição do reformismo muda com o tempo, passando da idéia de uma mudança radical, ainda que obtida por meios democráticos e graduais, à convicção de que bastam medidas que lhe regulem os mecanismos visando a um funcionamento mais eficiente e uma distribuição mais justa de benefícios. Essa mudança de posição é conseqüência dos próprios sucessos do reformismo através dos séculos, que demonstrariam que as enormes desigualdades se devem menos à essência do sistema que às dificuldades ou equívocos da "arrancada" inicial de origem do desenvolvimento (Settembrini, 1993), e como tal podem ser "corrigidos".

Essa perspectiva reformista mais estreita é a grande vencedora do final do século XX e início do XXI, onde não apenas as revoluções estão desacreditadas, mas cederam passagem a guerras sangrentas ou desmandos políticos de toda ordem, concomitante a uma "nova era de reformas", com características bastante particulares, e qualquer semelhança com idéias aparentemente longínquas não é mera coincidência.

Quanto ao termo eqüidade, conceitual e historicamente sua formulação está relacionada às noções de igualdade e liberdade e remetem à questão da justiça, dos direitos e deveres do homem/cidadão e do Estado. Os antecedentes dessas discussões estão nos séculos XVII e XVIII, culminando na Declaração dos Direitos do Homem e do Cidadão, de 1789, após a Revolução Francesa e, posteriormente, no século XX, na Declaração Universal dos Direitos do Homem, de 1948, e na Convenção Européia dos Direitos do Homem (1950), que marcam a nova era pós-Segunda Grande Guerra Mundial e serviram de guia para todas as constituições pos- 
teriores, dos diversos países. Nesse processo, embora as palavras sejam as mesmas - liberdade e igualdade - a validade jurídica e o significado conceitual mudou substancialmente, de forma estreitamente correlacionada uma à outra, ampliando-se e enriquecendo-se os seus conteúdos (Bobbio, 2000).

Esses dois valores se enraízam na concepção do homem como pessoa, na determinação do conceito de pessoa humana, e remetem um ao outro no pensamento político e na história. A igualdade, por um lado, como valor supremo de uma convivência ordenada, feliz e civilizada, como aspiração perene dos homens em sociedade e, por outro, como tema constante das ideologias e teorias políticas, vem sempre acoplada com a liberdade, e ambos têm na linguagem política um significado predominantemente positivo. Entretanto, no que se refere ao significado descritivo, axiológico e conceitual os dois termos são muito diferentes, embora apareçam com freqüência ideologicamente articulados.

Em termos muito sintéticos, liberdade indica um estado e igualdade uma relação: um estado do indivíduo e uma relação geral, desejável, entre indivíduos em sociedade (Bobbio, 2002). No que se refere ao significado descritivo do termo, no caso da liberdade a dificuldade está na sua ambigüidade na linguagem política, que permite diversos significados (qualidade ou propriedade da pessoa); e em relação à igualdade, a dificuldade está na sua indeterminação, pois é preciso especificar com que entes estamos tratando e em relação a que são iguais. Sendo assim, o conceito e o valor da igualdade mal se distinguem do valor e do conceito de justiça: consistindo numa relação, o que a torna um valor é o fato de ser justa, onde por justa se entende que "tal relação tem a ver, de algum modo, com uma ordem a instituir ou a restituir (uma vez abalada)" (Bobbio, 2002:-8). Em outras palavras, em si mesma a igualdade não é um valor, mas o é apenas na medida em que seja uma condição necessária, mas não suficiente, de um ordenamento justo, ou seja, "a liberdade é o bem individual por excelência, ao passo que a justiça é o bem social por excelência" (a virtude social de Aristóteles). Em suma, “a esfera da aplicação da justiça, ou da igualdade social e politicamente relevante, é a das relações sociais ... que remonta à distinção tradicional entre justiça comutativa" (relação entre as partes) e "justiça distributiva" (relação entre o todo e as partes, ou vice-versa) (Bobbio, 2002:1516). E isso remete ao problema de atribuir vantagens ou desvantagens, benefícios ou ônus, direitos ou deveres a indivíduos em sociedade, além da distinção entre uma igualdade justa e injusta. Pressupõe o estabelecimento da chamada regra de justiça, isto é, o modo pelo qual o princípio de justiça deve ser aplicado, a regra segundo a qual se deve tratar os iguais de modo igual e os desiguais de modo desigual, que assume importância em face da determinação da justiça, "concebida como o valor que preside a conservação da ordem social” (Bobbio, 2002: 20-21).

Portanto, a definição de igualdade que interessa discutir é a igualdade afirmada como propriedade das regras de distribuição (Oppenheim, 1993). Nessa perspectiva o que importa analisar é o caráter distributivo da própria regra. Igualdade e justiça possuem na realidade uma importante característica comum: ambas só podem ser sustentadas por regras que especificam como determinados benefícios ou ônus devem ser distribuídos. Portanto, a classificação de qualquer regra de distribuição como igualitária ou não igualitária não pode prescindir de considerações valorativas e nem toda distribuição igualitária é eqüitativa.

É necessário distinguir de modo mais preciso a igualdade perante a lei da igualdade de direito, da igualdade nos direitos (ou dos direitos) e da igualdade jurídica. A primeira é apenas uma forma jurídica e historicamente determinada de igualdade dos direitos; e a igualdade de direito é utilizada em contraposição à igualdade de fato; já a igualdade nos direitos significa o igual gozo, por parte dos cidadãos, de alguns direitos fundamentais constitucionalmente assegurados e, finalmente, a igualdade jurídica é aquela que transforma qualquer integrante de um grupo social em um sujeito dotado de capacidade jurídica. Assim, a igualdade nos direitos tem um âmbito mais amplo que o da igualdade perante a lei, e a igualdade jurídica tem um âmbito mais restrito (Bobbio, 2002).

Um outro princípio de igualdade, considerado um dos pilares do Estado de democracia social (tal como a igualdade perante a lei representou um dos pilares do Estado liberal) é o da igualdade de oportunidades ou de chances, ou de pontos de partida, que abstratamente não tem nada de novo, a menos que seja definido seu conteúdo "com referência a situações específicas e historicamente determinadas" (Bobbio, 2002:30). O que esse princípio tem de inovador, nos estados sociais e economicamente avançados, é o fato de ter se difundido de forma importante, como "conseqüência do predomínio de uma concepção conflitualista global da sociedade, segundo a qual toda a vida social é considerada uma grande competição para a obtenção de bens escassos" (Bobbio, 2002:31). Dito de outra forma, o princípio da igualdade 
de oportunidade como princípio geral tem como objetivo colocar todos os membros de determinada sociedade na condição de participar da competição pela vida, isto é, pela conquista do que é vitalmente significativo, a partir de posições iguais de partida. E Bobbio, assim como outros autores, chama a atenção para o fato de que para colocar indivíduos desiguais de nascimento nas mesmas condições de partida pode ser necessário favorecer os mais pobres e desfavorecer os mais ricos, numa distribuição desigual. Dessa forma a desigualdade torna-se instrumento da igualdade, ao corrigir uma desigualdade anterior.

Obviamente, a definição de quais devem ser essas condições de partida e quais as condições materiais a serem consideradas iguais não é dada $a$ priori nem é uma questão trivial. Definir os bens em relação às necessidades remete à determinação do que é ou não é um bem, e de quais são as necessidades dignas de serem satisfeitas e em relação às quais se considera justo que os homens sejam iguais. Sendo assim, segundo Bobbio (2002), nada é mais indeterminado do que a fórmula a cada um segundo suas necessidades, transformada em ideal-limite da sociedade comunista, mas por outro lado, é o princípio mais igualitário de todos, já que se considera que os homens são mais iguais entre si (ou menos diversos) com relação às necessidades do que, por exemplo, em relação às capacidades (Oppenheim, 1993). E mesmo que seja possível essa determinação, o problema ainda não estaria resolvido: a igualdade deve ser absoluta ou relativa?

De qualquer forma, ao longo do decurso histórico existem diversas formas de doutrinas igualitárias, freqüentemente em conflito uma com as outras, mas entre os próprios princípios de justiça, uns são mais igualitários que outros e um princípio será mais igualitário quanto menores forem as diferenças presumíveis entre os homens com relação ao critério adotado. Sendo assim, é importante distinguir entre desigualdades naturais e desigualdades sociais e desde Rousseau (Discurso sobre a Origem da Desigualdade entre os Homens), a meta é a eliminação da segunda. E o que caracteriza as ideologias igualitárias em relação a todas as outras ideologias sociais, que exigem ou admitem formas particulares de igualdade, é a exigência de uma igualdade também material, distinta da igualdade perante a lei e da de oportunidade.

Constata-se que, no debate político, a igualdade constitui um dos valores fundamentais em que se inspiraram as filosofias e ideologias de todos os tempos, mas em todos os contextos em que é invocada, é sempre uma igualdade determinada e o que lhe atribui carga positiva não é a igualdade em si, mas a sua extensão a todos. Sendo assim, e sendo uma máxima qualquer de justiça, duas questões devem ser respondidas e são fundamentais: igualdade em quê? E entre quem? (Bobbio, 2000, 2002).

Liberalismo e igualitarismo têm suas raízes em concepções da sociedade profundamente diversas: "individualista, conflitualista e pluralista, no caso do liberalismo; e totalizante, harmônica e monista, no caso do igualitarismo..." E diversos também são os modos de conceber a natureza e as tarefas do Estado: "limitado $e$ garantista, o Estado liberal; intervencionista e dirigista, o Estado dos igualitários" (Bobbio, 2002:42). Segundo Bobbio, essas diferenças não excluem porém a possibilidade de sínteses teóricas e soluções práticas de compromisso entre liberdade e igualdade, uma vez que esses dois valores, mais a ordem, são fundamentais de toda convivência civilizada e considerados também como complementares.

Enquanto igualitarismo e não-igualitarismo são totalmente antitéticos, igualitarismo e liberalismo são parcialmente antitéticos, o que não anula o fato de historicamente serem considerados antagônicos e alternativos. O liberalismo admite a igualdade de todos não em tudo, mas somente em algo (parcialmente igualitário), algo este constituído habitualmente pelos chamados direitos fundamentais, ou naturais ou humanos, que são as várias formas de liberdade pessoal, civil e política, enumeradas progressivamente pelas várias Constituições dos Estados nacionais desde o fim do século XVIII até hoje, e reconfirmadas após a Segunda Guerra Mundial, em documentos internacionais (Bobbio, 2000). Entretanto, as doutrinas igualitárias sempre acusaram o liberalismo de ser defensor e protetor de uma sociedade econômica e, portanto, politicamente não igualitária. Para Marx, a igualdade da Revolução Francesa apenas serviu para liberar a força de trabalho necessária ao desenvolvimento capitalista. "Da crítica das teorias igualitárias contra a concepção e a prática liberal do Estado é que nasceram as exigências de direitos sociais, que transformaram profundamente o sistema de relações entre o indivíduo e o Estado, até mesmo nos regimes que se consideraram continuadores, sem alterações bruscas, da tradição liberal do século XIX" (Bobbio, 2002:42).

Do ponto de vista da filosofia da história, a afirmação dos direitos do homem, antes puramente doutrinal e prático-política, ganha novos contornos a partir das Declarações dos Direitos do Homem e do Cidadão do fim do século XVIII (1789) e isto representou uma inversão 
radical na história secular da moral (Bobbio, 2000). Na história do pensamento moral e jurídico, o ponto de vista predominante foi mais pelo lado dos deveres do que pelo dos direitos. Para a passagem do código dos deveres para o dos direitos foi preciso que o problema fosse observado não apenas do ponto de vista da sociedade, mas também do ponto de vista do indivíduo - uma verdadeira revolução.

A doutrina dos direitos naturais pressupõe uma concepção individualista da sociedade $\mathrm{e}$ portanto do Estado, continuamente em conflito com a bem mais sólida e antiga concepção orgânica, segundo a qual a sociedade é um todo que está acima das partes. A concepção individualista custou a avançar porque foi geralmente considerada como fomentadora de ruptura da ordem constituída e sempre foi criticada, mesmo às portas da Revolução Francesa e no período da restauração, entre outras coisas, por "destruir a idéia de dever" (Bobbio, 2000). Significa que antes vem o indivíduo, isolado, que tem valor em si mesmo, e depois o Estado, que por sua vez, é feito pelo indivíduo. Nessa inversão de relação entre o indivíduo e o Estado, inverte-se também a relação tradicional entre direito e dever: no que concerne aos indivíduos, vêm antes os direitos e depois os deveres; no que concerne ao Estado antes os deveres, depois os direitos. O mesmo ocorre em relação à justiça: em uma concepção orgânica, a definição mais apropriada é que cada uma das partes que compõem o corpo social deve desempenhar a função que lhe é própria (platônica), enquanto na concepção individualista é justo que cada um seja tratado de modo a poder satisfazer suas próprias necessidades e alcançar seus próprios fins, sendo o primeiro deles a felicidade. Contraditoriamente, o individualismo é a base da democracia (cada cabeça um voto), entendida como a forma de governo onde todos são livres para tomar decisões em questões que lhe dizem respeito e têm poder de fazê-lo; liberdade e poder que derivam do reconhecimento de alguns direitos fundamentais, inalienáveis e invioláveis, que são os direitos do homem". Sendo assim, o individualismo sempre se contrapôs às concepções holistas da sociedade e da história, qualquer que seja a sua proveniência, ao mesmo tempo que é a base das concepções democráticas da sociedade e dos direitos fundamentais.

Desde sua primeira aparição no pensamento político dos séculos XVII e XVIII, até o primeiro documento histórico depois do fim da guerra, a Carta das Nações Unidas, a doutrina do direito dos homens avançou muito. E nessa história progressiva, foram percorridas diver- sas etapas: a primeira foi a "constitucionalização, que transformou uma aspiração ideal secular .... em um direito público subjetivo, ainda que no restrito âmbito de uma nação" (Bobbio, 2000:481). A segunda, que dura até hoje, numa evolução contínua, foi a sua progressiva extensão - iniciando no próprio interior dos direitos de liberdade (de associação, por exemplo), passando para o reconhecimento dos direitos políticos até a concessão do sufrágio universal masculino e feminino (passagem do Estado liberal ao Estado democrático), e a introdução dos direitos sociais (Estado democrático e social). E a terceira etapa, que teve seu ponto de partida na Declaração Universal dos Direitos dos Homens (1948), é a da universalização, isto é a transposição da sua proteção do sistema interno para o sistema internacional, embora mais hipotética do que real (Bobbio, 2000).

Se pode acenar ainda, segundo Bobbio, a uma quarta etapa: a de especificação dos direitos, uma vez que a expressão "direito dos homens" é demasiado genérica e não é suficiente, sendo necessário, desde o início, diferenciar os direitos do homem em geral dos direitos do cidadão, no sentido que a este último se podem atribuir direitos ulteriores. Essa especificação continuou, porém, na medida da necessidade de exigências específicas de proteção, segundo sexo (direito das mulheres), fase da vida (direito das crianças, dos idosos) ou condições específicas de proteção (de enfermos, deficientes, doentes mentais etc.).

Todo esse desenvolvimento é conseqüente à idéia original do indivíduo, considerado em todos os seus aspectos como titular de direitos, isto é, de pretensões que lhe devem ser reconhecidas em relação à sociedade. Obviamente, a pretensão não significa satisfação, e "à medida que as pretensões aumentam, a sua proteção torna-se cada vez mais difícil": os direitos sociais são mais difíceis que os de liberdade; a proteção internacional é mais difícil que aquela no interior do próprio Estado, exacerbando o conflito entre o ideal e o real. Mas dada a "vastidão que assumiu atualmente o debate sobre os direitos dos homens como um sinal de progresso moral da humanidade, ... esse crescimento ...deve ser medido não pelas palavras, mas pelos fatos. De boas intenções está pavimentado o caminho para o Inferno" (Bobbio, 2000:483).

Pode-se afirmar que enquanto os direitos individuais se inspiram no valor primário da liberdade, os direitos sociais se inspiram no valor primário da igualdade. São direitos que tendem senão a eliminar, a corrigir desigualdades, que nascem das condições de partida, econômicas e sociais, mas também, em parte, das 
condições naturais de inferioridade física. Entretanto, antes de serem antitéticos entre si, para Bobbio (2000), o reconhecimento de alguns direitos sociais fundamentais é o pressuposto ou a pré-condição para um efetivo exercício dos direitos de liberdade. $\mathrm{E}$ a liberdade positiva (liberdade como poder) corresponde à igualdade social, isto é, igualdade de oportunidade, e exigi-la significa exigir que se concretizem os direitos sociais, tema que tem sido bastante negligenciado, seja pela direita que sempre exaltou de forma particular os direitos de liberdade, especialmente as liberdades econômicas, seja pela esquerda, que nos Estados comunistas exaltou os direitos sociais em detrimento dos direitos de liberdade, e após a queda do Muro de Berlim "parece seguir a direita em seu próprio terreno" (Bobbio, 2000:501).

A noção de eqüidade é caudatária desse percurso histórico, e está estreitamente vinculada à idéia de igualdade, na perspectiva discutida acima. Na revisão da literatura, a eqüidade, de uma maneira geral, se refere " a diferenças que são desnecessárias e evitáveis, além de consideradas injustas" (Whitehead, 1992:431) e, portanto, passíveis de intervenção por meio das políticas dos diversos setores, inclusive o de saúde. Para que uma determinada situação seja identificada como injusta, suas causas deverão ser examinadas e julgadas no contexto mais amplo da sociedade (Mooney \& Jan, 1997), o que remete necessariamente aos valores e princípios morais, éticos e político-ideológicos que orientam a política setorial num dado país, em um dado momento histórico. Sendo assim, em função do conjunto de valores predominantes, o termo eqüidade pode ganhar diferentes conotações ao longo do tempo e em distintas sociedades, sendo vários os seus significados e raro o consenso em torno de uma definição (Almeida et al., 1999). Além disso, existem diversas maneiras de medir a justiça social e cada uma delas produz diferentes resultados. Portanto, a definição de eqüidade escolhida para ser operacionalizada e as formas de medila, refletem os valores e escolhas de determinada sociedade em momentos específicos. Essas considerações não são triviais e revelam os objetivos estratégicos de diferentes definições.

Tratando-se, portanto, de uma meta ideal que marcou o século XX, esteve extremamente presente no final do milênio e continua cada vez mais atual no início do século XXI, e cuja urgência não se pode mais ignorar, é surpreendente que esteja subsumida por uma adoração do livre mercado (Bobbio, 2000).

A partir dos anos 1970-1980, a discussão da crise do Estado de Bem-Estar Social, na esteira da crise econômica, suscitou o questionamento dos resultados em termos de benefícios dos investimentos realizados nos sistemas de saúde. Até então, a valorização da noção de igualdade havia permeado de forma importante os princípios que nortearam a construção dos sistemas de serviços de saúde no século XX, embutida na percepção do direito à saúde como direito de cidadania, sobretudo, depois da Segunda Grande Guerra e sob a égide das políticas econômicas e sociais de cunho keynesiano. A idéia central voltava-se para assegurar o direito de consumo de serviços de saúde, em caso de necessidade, para todos os indivíduos, independente da sua condição social e econômica. Em outras palavras, o princípio dessa estruturação era que todo cidadão que necessitasse de atenção à saúde deveria ter direito assegurado de acesso aos serviços. E somente a forte intervenção do Estado, como provedor e financiador de serviços, através da arrecadação fiscal ou de contribuições sociais, poderia promover a eqüidade, entendida como igualdade de oportunidades no consumo de bens e serviços de saúde, segundo necessidades. Esse princípio foi traduzido na prática, de diversas maneiras nos distintos países e sistemas de saúde, com diferentes resultados que, de forma geral, passaram a ser questionados a partir dos anos 70 , com a crise econômica e a subseqüente crise de custos no setor.

O debate conceitual sobre a eqüidade retoma força, portanto, no final do milênio, a partir dos anos 80, no âmbito das políticas de reforma, que ao mesmo tempo em que questionam a extensa intervenção estatal em saúde (leia-se o montante de financiamento público, a provisão estatal de serviços etc.), preconizam a reforma do Estado e dos sistemas de saúde, para atuarem de forma mais eficiente e efetiva e com melhores resultados em termos de eqüidade. Ao longo dos anos 90, esse debate se amplia consideravelmente, frente ao aumento inquestionável das desigualdades, sobretudo no Sul do planeta, tornando-se um dos principais pontos da agenda de discussão sobre as reformas (do Estado e setoriais) nos fóruns nacionais e internacionais.

Em 1995, a Organização Mundial da Saúde definia a reforma do setor como um processo sustentado de mudanças fundamentais na política de saúde e nos arranjos institucionais, coordenado pelo Estado, com a finalidade de melhorar o funcionamento e o desempenho do setor, visando alcançar melhores níveis de saúde da população (WHO, 1995). A reforma na saúde estaria referida então à definição de prioridades, refinamento da política de saúde e re- 
forma das instituições que implementam essas políticas (Janovsky \& Cassels, 1995). Em 1997, Knowles \& Leighton (1997), reconhecendo a ausência de definições precisas e de várias e diferentes conotações, definiam reforma em saúde colocando ênfase no elenco de objetivos e na abrangência da reforma como mais importante do que uma definição precisa, reiterando as premissas acima.

Outros autores definem a reforma setorial como mudanças específicas para melhorar a eficiência, a eqüidade e a eficácia dos sistemas de serviços (Berman, 1995), ignorando as inerentes contraposições implicadas nessas relações. E formulam-se também tipologias de reforma: umas levando em consideração a abrangência da mudança e a forma de implementação (Ham, 1997) - reforma big-bang, incremental, "de baixo para cima" e incipiente - e outras que apóiam-se na definição das "dimensões estratégicas" ou "macrofunções" dos sistemas de saúde, que devem ser objeto de reforma (Berman \& Bossert, 2000) - financiamento, prestação de serviços, incentivos, regulação e informação.

Na conjuntura atual de reformas setoriais, o princípio da eqüidade, presente na agenda reformadora, freqüentemente está condicionado aos objetivos de eficiência, submetida aos "limites de caixa" e de custo-efetividade, que por sua vez, não inclui a análise dos objetivos de determinada política e exclui explicitamente a valoração dos fins que a justificam, cuja definição e implementação pertencem ao campo político e não à análise técnica. As políticas restringem-se, assim, a determinar a alternativa mais eficiente e efetiva para alcançar determinados objetivos, porém não levam em consideração os resultados de determinada ação para a sociedade em seu conjunto. Em outras palavras, embora seja desejável e necessário que as ações em saúde sejam mais efetivas e eficientes, a questão das diferentes necessidades de distintos grupos populacionais é reduzida à diminuição da intervenção estatal e do financiamento público, traduzidas nas políticas de focalização (nos mais pobres) e de privatização, apregoadas como mais eqüitativas.

Nenhuma dessas reflexões e propostas avança em termos conceituais, partindo da premissa básica de que as reformas sanitárias são processos tecnocráticos, decorrência natural da "grande transformação" na qual o mundo está envolvido há mais de duas décadas. Esse pressuposto permite que, por um lado, somente se identifique como "reforma" aquelas mudanças que se adeqüem a determinados referenciais, como por exemplo, "as reformas orientadas pa- ra o mercado”, excluindo-se, em conseqüência, todas as outras mudanças de política de saúde que não levem em consideração esse paradigma. E, por outro, que se particularize o caráter social da política de saúde, isto é, que se redefina o direito à saúde, excluindo-o do elenco dos benefícios sociais, segmentando-se diferentes beneficiários, determinando-se prioridades e focalizando-se benefícios e serviços para "pobres e necessitados", alegando-se recursos escassos e impossibilidade de atender a uma demanda inerentemente infinita.

\section{Política social e política de saúde}

Como nos recorda Santos (1998), o problema da escassez de recursos para satisfazer as necessidades e demandas dos membros de uma sociedade não é novo e sempre esteve presente no pensamento político e econômico, durante séculos, inserindo-se no âmbito da questão mais ampla sobre a possibilidade de manutenção da ordem social. E são bem discutidas na literatura as vinculações entre a consolidação e complexificação do Estado moderno, e o desenvolvimento da ação política como forma de construção da ordem social. A crença numa ordem política promovida desde o Estado e organizadora da sociedade, simultânea ao desenvolvimento do sistema econômico capitalista, são as bases da expansão da capacidade de regulação social do Estado, da criação das representações democráticas e da idéia dos direitos sociais que sustentam os princípios de cidadania (Baltodano, 1997). A dinâmica dessa intervenção estatal no campo social repercutirá de forma importante e específica em cada sociedade.

Em termos muito sintéticos, num longo processo histórico que atravessa séculos, mais precisamente nos séculos XIX e XX, a institucionalização paulatina de direitos sociais, como parte do desenvolvimento do princípio da cidadania, inspirado na idéia liberal de igualdade, gerou políticas públicas voltadas seja para a compensação das desigualdades produzidas pela dinâmica de expansão do capital, seja como moeda de troca no jogo político.

A idéia de uma política setorial para a saúde, tal como para outras áreas sociais, não existia antes da segunda metade do século XIX. Historicamente, através dos séculos, o discurso médico-científico da saúde se imbricou com o âmbito social, permitindo a emergência do discurso da saúde pública e da política de saúde como campos específicos de intervenção do Estado. Entretanto, esse processo não se deu 
de forma linear nem tampouco essa intervenção foi uniforme, mas historicamente determinada, como resposta a diferentes demandas e necessidades em espaços e épocas distintas (vejam-se as diferentes e complementares etapas de constituição da medicina social na Europa - da medicina do Estado na Alemanha, da medicina urbana na França e da medicina da força de trabalho na Inglaterra, discutidas por Foucault, 1979).

Na realidade, a partir do século XVIII, observa-se a emergência da saúde e da doença como problemas que exigem, de uma maneira ou de outra, um encargo coletivo; além disso, e mais importante, observa-se também um outro processo - o surgimento da idéia do bemestar físico da população em geral (saúde) como um dos objetivos essenciais do poder político. Já no final do século XIX, a ampliação e dominância da racionalidade científica médica foi acompanhada de um crescente desenvolvimento e dependência das estatísticas. E no século XX, o espetacular desenvolvimento da tecnologia médica reforçou o lado curativo assistencial do cuidado da saúde. Ou seja, a importância da medicina na política de saúde tem origem no cruzamento entre uma nova economia analítica da assistência (inicialmente voltada para os pobres e posteriormente para a população como um todo), incluindo a transformação dos hospitais em local privilegiado de produção de saúde e de conhecimentos sobre as doenças, e a emergência de um "policiamento" da saúde em nível da população (Foucault, 1979). Em síntese, numa outra clave analítica Foucault também apontou que o conceito de população, estatisticamente esquadrinhada e ordenada, e, posteriormente, o de política de saúde, emergiram e se realizaram no processo de disciplinamento da sociedade, ou seja, saúde e doença tornaram-se categorias que integram os sistemas de administração e controle da população, e a política de saúde o campo privilegiado de regulação de várias tensões sociais (Foucault, 1979; Rosen, 1980, 1994). Em outras palavras, são elementos constitutivos do estabelecimento de uma determinada ordem social.

Os direitos e deveres dos indivíduos em relação à sua saúde e a dos outros, o mercado onde interagem as demandas e as ofertas de cuidados médicos, as intervenções do poder na ordem da higiene (prevenção) e das doenças (cura), a institucionalização e defesa da relação privada com o médico (predomínio da medicina científica), marcam o funcionamento global da política de saúde do século XIX (Foucault, 1979). E na segunda metade do século XX, a va- lorização da noção de igualdade de oportunidade de acesso a serviços passou a constituir um dos princípios que nortearam a construção dos sistemas de saúde, embutida na percepção do direito à saúde como direito de cidadania, sobretudo depois da Segunda Grande Guerra e sob a égide das políticas econômicas e sociais de cunho keynesiano, isto é, com forte intervenção do Estado como provedor e financiador de serviços, por meio da arrecadação fiscal ou de contribuições sociais.

Essa análise é pertinente para os países desenvolvidos do Norte, sobretudo europeus, mas para a nossa região a história é outra. Nossa evolução histórica está marcada pela constituição de estados economicamente dependentes; sociedades altamente segmentadas, com consideráveis níveis de exclusão e marginalidade social; bases territoriais socialmente desintegradas; instituições com baixa capacidade de implementação de políticas e de regulação social; e estruturas de direitos de cidadania extremamente frágeis e parciais. Estados com uma “inserção subalterna nos mercados internacionais" e pautada por endividamento progressivo e perverso (Baltodano, 1997:56).

A intervenção do Estado na saúde, embora importante num primeiro momento, vinculou as atividades médico-sanitárias (beneficência pública, salubridade), de forma estreita e centralizada, aos interesses econômicos imediatos e às necessidades do comércio internacional. $\mathrm{E}$ a transformação da atenção médica somente se deu depois dos anos 30 do século passado, com importante ênfase na atenção hospitalar, mas de forma privatizada ou fortemente subsidiada pelo Estado e voltada para grupos particulares. Essa estruturação foi coerente com a lógica de cidadania regulada (Santos, 1979), que norteou a forma de segmentação particularista que adquiriu a política social na região, privilegiando os sistemas corporativos da sociedade. Este modelo conviveu também com variadas formas de controle social de tipo oligárquico e de coerção estatal, pela forte presença militar no poder, sobretudo no Cone Sul, que impediram a formação de espaços públicos e o desenvolvimento da capacidade de intervenção da sociedade e de canais efetivos de participação e controle social. Acrescenta-se ainda a este panorama a histórica influência dos organismos internacionais na formulação e implementação de políticas na região (Malloy, 1993; Melo \& Costa, 1994).

O resultado foi a implementação de políticas sociais pouco inclusivas, ineficientes e inefetivas e o desenvolvimento de complexos médico industriais desregulados, com alto grau de 
autonomia, que cresceram à sombra do Estado ou francamente subsidiados com recursos públicos.

\section{A agenda de reforma da política social e de saúde}

Na América Latina, o debate sobre a política de bem-estar social prosperou no contexto de crítica aos regimes ditatoriais, pouco aprofundando uma discussão da política social em si, a não ser como "não-política" ou como a expressão material da pouca prioridade conferida pelos regimes burocráticos-autoritários aos aspectos distributivos. A ênfase estava posta então nos efeitos regressivos (perversos) das políticas públicas não sociais, e na pressuposição da inexistência de uma política social (segunda metade dos anos 60 e início dos 70). E, posteriormente (da segunda metade dos 70 a primeira dos 80), na crítica da racionalidade que havia incorporado a política social a uma específica forma de acumulação - a constituição de complexos empresariais em torno à sua dinâmica (Melo, 1998).

Esse debate se processa, porém, em escala planetária a partir da segunda metade dos anos 70 do séc. XX, capitaneado pelo Banco Mundial, que enfatiza a contraposição entre eficiência (alocativa) e eqüidade, retomando a cantilena crescimento versus distribuição, e passando a difundir a fórmula de "redistribuição (apenas) com crescimento". Introduz-se também a abordagem das "necessidades básicas" (Melo, 1998; Melo \& Costa, 1994). Ao mesmo tempo em que se reconhecia a importância da intervenção estatal no setor social, exacerbava-se a crítica à sua efetividade e capacidade resolutiva, sendo que a questão central seria a incapacidade das políticas do Estado de atenderem às necessidades básicas da população alvo, isto é, os mais necessitados. O novo conceito que passa a ser então difundido é o de "má alocação", ou seja, o problema não era a irrelevância do gasto social público mas a sua "má utilização", uma vez que os benefícios eram inexpressivos frente aos custos associados à manutenção de estruturas organizacionais gigantescas, caras e inefetivas.

A análise centrou-se então na forma de operacionalização da política social e no seu caráter burocrático, excludente, ineficiente e ineficaz. A reforma administrativa e a descentralização (que além de "aproximar os decisores e excutores das políticas das necessidades de suas comunidades e populações, poderiam superar o "gigantismo burocrático") ocupam lu- gar de destaque nesse debate. A partir de "reengenharias" institucionais e mudanças "nas regras do jogo", influência clara do paradigma neo-institucionalista, espera-se obter maior eficiência, eqüidade e a concomitante diminuição de comportamentos predatórios e nocivos, utilizando-se mecanismos que incentivem a competição (Almeida, 1995, 1999, 2001; Melo, 1998). A ênfase foi posta, assim, na reforma das leis (Constituição) e da arquitetura legal dos programas e políticas, entendidas como estruturas de subsídios e incentivos a serem redefinidos para modelar novos comportamentos. Uma vez mais o Banco Mundial tomou a dianteira, agora na área social: ao mesmo tempo que criou um fundo com o objetivo de aliviar as conseqüências econômicas e sociais adversas dos programas de ajuste, anunciava sua entrada ativa nos processos de reformulação das políticas setoriais (Banco Mundial, 1989, 1993).

A natureza dual da questão saúde para a região - como um fim em si mesma e como um meio para fomentar o desenvolvimento - já havia sido assinalada por documentos produzidos anteriormente pela CEPAL (1990), que subsidiaram a análise do Banco, e a proposta de política de saúde, que emergiu do embate entre as agências internacionais que atuam na região, foi finalmente endossada também pela Organização Pan-Americana da Saúde (OPS, 1995; OPS/CEPAL, 1994). As condicionalidades dos credores internacionais passaram então a incluir recomendações explícitas para a reforma das políticas sociais, incluídas as de saúde, defendendo-se uma melhor utilização dos recursos escassos, que deveriam ser direcionados para intervenções que diminuíssem a "carga de doença” e fossem comprovadamente custo-efetivas (Banco Mundial, 1993).

Em trabalhos anteriores analisei essa agenda e os respectivos modelos de reorganização dos sistemas de saúde com maiores detalhes. Para o que nos interessa discutir aqui, basta reter que essa nova agenda constitui um conjunto articulado de proposições: redefinição do mix público e privado e separação de funções de financiamento e provisão, diminuição da intervenção do Estado na provisão de bens e serviços e fortalecimento de seu poder regulatório; direcionamento da esfera pública para os grupos sociais "mais necessitados" (que não tenham condições de satisfazer suas necessidades a partir da oferta desses serviços no mercado) e reorientação da oferta pública, priorizando a prestação de serviços básicos e de baixo custo, o que permitiria maior abrangência e eficácia; descentralização funcional das responsabilidades de prestação para os níveis sub-na- 
cionais de governo; introdução de mecanismos competitivos (criando-se quase-mercados ou mercados regulados) e de contenção, controle e recuperação de custos, como forma de melhorar a eficiência; e estímulo à privatização, sobretudo em relação à assistência médica, com fomento do mercado privado de serviços, e da previdência social privada.

Identificam-se elementos dessa agenda reformista em praticamente todos os processos de reforma dos sistemas de saúde na região, introduzidos numa perspectiva (teórica) de conciliar eficiência e eqüidade. Para tal, modificaram-se as regras de financiamento e os benefícios, como também a participação dos agentes públicos e privados, separando-se as funções de regulação, provisão e financiamento. Estimulou-se uma maior participação do setor privado na provisão de serviços, e instituiu-se a competição entre as entidades seguradoras e prestadoras de serviços, implantando-se formas de quase-mercado na provisão pública de serviços. A idéia de seguro é dominante e existem diferenças importantes nas combinações entre seguro social (público e solidário) e seguros de saúde privados, estruturando-se complicados mix público/privado (Almeida, 1999, 2002; CEPAL, 2000, 2001; Sojo, 2001).

\section{Para concluir}

As reformas recentes implementadas na América Latina exacerbaram alguns dos traços constitutivos das sociedades na região e criaram novos problemas ao privilegiar uma perspectiva economicista, pragmática e restritiva. Assiste-se assim, à substituição dos valores de solidariedade e igualdade de oportunidade pelos de um "individualismo utilitarista radical" (Mateucci, 1993), mais característico de séculos passados do que do início de um novo milênio; e do princípio de "necessidades de saúde ou de serviços de saúde" pelo de "risco", monetarizado e definido segundo a posição social e econômica do indivíduo. A partir dos anos 80, passou-se a acreditar na possibilidade de harmonizar os interesses particulares egoístas ou de fazer coincidir a utilidade particular com a pública, a partir da aplicação à saúde, por analogia, dos conceitos de mercado e de utilidade formulados para a economia.

Em termos gerais, a situação dos sistemas de saúde não é animadora: pode-se dizer que, na última década do século $\mathrm{XX}$, apesar das imensas desigualdades regionais, o financiamento público pouco se alterou ao mesmo tempo que o gasto privado se manteve alto, com redução do componente direto do gasto das famílias em favor do gasto com seguros privados e esquemas de pré-pagamento, das empresas e outras organizações da sociedade, além de que diminuiu a cobertura populacional (com exceção de alguns países como Brasil e Colômbia), piorou o acesso e a utilização dos serviços de saúde e deteriorou-se consideravelmente a capacidade instalada setorial, majoritariamente pública, também com poucas e honrosas exceções (Almeida, 2002).

Pode-se afirmar que, em alguns casos, as reformas implementadas foram muito mais radicais que as dos países do Norte, abrangendo vários âmbitos - do financiamento à reorganização dos sistemas de serviços - e implicaram em importantes conflitos com o princípio de solidariedade e eqüidade, aumentando de forma importante a complexidade inerente aos sistemas de saúde. Além disso, aprovaram princípios legais que institucionalizaram o direito à saúde como benefício social, formalizaram a cobertura universal e o comprometimento com o princípio da eqüidade (como Brasil e Colômbia), mas a operacionalização dessas mudanças, de fato, tem aumentado a fragmentação e segmentação dos sistemas de saúde e não tem superado as desigualdades, além de deixar a desejar em termos de eficiência.

Apesar da necessária capacidade regulatória e de implementação, a reforma do aparelho de Estado não se efetivou como desejado, além de que o desenvolvimento dessa capacitação foi extremamente prejudicado pelo stress fiscal e desprestígio das instituições públicas e dos funcionários do Estado.

Em síntese, o dilema genuíno entre a administração de recursos escassos (eficiência) e a superação das desigualdades (justiça social) foi extremamente exacerbado nas últimas décadas, quando a crença na possibilidade de equilibrar esses dois parâmetros foi questionada, e as políticas neoliberais enfatizaram o individualismo e vincularam a política social estritamente ao cálculo econômico, exacerbando o conflito entre valores e revigorando a contabilidade ética que lhe é subjacente (Santos, 1998). E esse dilema é especialmente importante na região latino-americana, uma vez que as condicionalidades externas têm encontrado forte aceitação nacional e a experimentação tem proliferado de forma acrítica.

Seria necessário, portanto, retomar a discussão das políticas sociais numa outra perspectiva, como por exemplo sugere Santos (1998: 51), ao defini-las como metapolítica, isto é, como a "matriz de princípios que justifica o ordenamento de quaisquer outras políticas”. Isto 
significa revigorar a discussão dos princípios e valores que lhe são subjacentes, e definir princípios de justiça coerentes e consistentes nos quais se apoiar, além de operacionalizá-los de forma efetiva. Resta portanto, incluir nessa equação a negociação política.

Além disso, embora seja necessário fazer escolhas, definir prioridades para a atuação do Estado no setor, a solução não está em "transferir o problema do âmbito político, significativamente indeterminado e altamente valorativo, para o universo do discurso lógico" (técnico), supostamente neutro e que obedece a regras racionalmente irrecusáveis (Santos, 1998:40), como se vem fazendo. Essa dinâmica requer o ordenamento de preferências, que implica na introdução de condicionalidades (nacionais e locais) impostas pela realidade, onde o discurso e a retórica dos decisores e de seus críticos se efetiva. E esse ordenamento de preferências não pode ser logicamente deduzido, o que significa que não é possível resolvê-lo a partir unicamente da lógica científica (técnica). Em outras palavras, é preciso lembrar que se está tratando de decisões de políticas que pressupõem a distribuição de cotas distintas de benefícios e sacrifícios entre os indivíduos de uma sociedade, que assegurem a minimização do conflito social e alguma ordem social, o que requer procedimentos adequados. A questão substantiva, portanto, é definir qual seria a "distribuição justa da relação sacrifício/benefício entre os indivíduos da sociedade" (Santos, 1998:51). Recai, assim, na lógica política do "cálculo do dissenso", isto é, qual o consenso possível, ou o dissenso suportável em determinada sociedade, em determinada conjuntura. Refere-se em última instância, ao grau de desigualdade (e de conflito) que uma sociedade está disposta (ou consegue) suportar.

\section{Agradecimentos}

Agradecemos o apoio da Red de Investigación en Sistemas y Servicios de Salud en el Cono Sur de América Latina (Red), uma vez que este artigo é parte do trabalho de pesquisa desenvolvido no Programa EquityOriented Health Policy Analysis in Latin America, financiado pelo International Development Research Center (IDRC) /Canadá e desenvolvido pela Red, em colaboração com a Escola Nacional de Saúde Pública, Fundação Oswaldo Cruz. Agradecemos também à revisão atenta e às sugestões extremamente pertinentes dos(as) revisores(as) anônimos(as).

\section{Referências}

ALMEIDA, C. M., 1995. As Reformas Sanitárias nos Anos 80: Crise ou Transição? Tese de Doutorado. Rio de Janeiro: Escola Nacional de Saúde Pública, Fundação Oswaldo Cruz.

ALMEIDA, C. M., 1999. Reforma do estado e reforma de sistemas de saúde: Experiências internacionais e tendências de mudança. Ciência \& Saúde Coletiva, 4:263-286.

ALMEIDA, C. M., 2001. Reforma del estado y reforma de sistemas de salud. Cuadernos Médico-Sociales, 79:27-58.

ALMEIDA, C. M., 2002. Reforma de sistemas de serviços de saúde e eqüidade na América Latina e Caribe: Algumas lições dos anos 90. Cadernos de Saúde Pública, 18:905-923.

ALMEIDA, C. M.; TRAVASSOS, C.; PORTO, S. \& WARGAS, T. B. F., 1999. A Reforma Sanitária Brasileira: Em Busca da Eqüidade. Washington, DC: Organização Pan-Americana da Saúde. 
BALTODANO, A. P., 1997. Estado, soberanía y políticas públicas en América Latina y estado: Ciudadanía y política social en América Latina. In: Globalización, Ciudadanía y Política Social en América Latina: Tensiones y Contradicciones (A. P. Baltodano, ed.), pp. 16-66, Caracas: Nueva Sociedad.

BANCO MUNDIAL, 1989. El financiamiento de los servicios de salud en los paises en desarrollo. Una agenda para la reforma. In: Economia de la Salud - Perspectivas para la America Latina. Publicación Científica 517. Washington, DC: Organización Panamericana de la Salud/Organización Mundial de la Salud.

BANCO MUNDIAL, 1993. World Development Report: Investing in Health. Washington, DC: World Bank.

BERMAN, P. \& BOSSERT, T. J., 2000. A Decade of Health Sector Reform in Developing Countries: What Have We Learned? Boston: Data for Decision Making Project, International Health Systems Group, Harvard School of Public Health. (mimeo.)

BERMAN, P., 1995. Health sector reform: Making health development sustainable. In: Health Sector Reform in Developing Countries: Making Health Development Sustainable (P. Berman, ed.), pp. 1333, Boston: Harvard University Press.

BOBBIO, N., 2000. Teoria Geral da Política - A Filosofia Política e as Lições dos Clássicos. 2a Ed. Rio de Janeiro: Editora Campus.

BOBBIO, N., 2002. Igualdade e Liberdade. 5a Ed. Rio de Janeiro: Ediouro.

CEPAL (Comisión Económica para América Latina y el Caribe), 1990. Transformación Productiva con Equidad - La Tarea Prioritaria del Desarrollo de América Latina y el Caribe en los Años Noventa. Santiago de Chile: Naciones Unidas/CEPAL.

CEPAL (Comisión Económica para América Latina y el Caribe), 2000. Equidad, Desarrollo y Ciudadanía. Santiago de Chile: Naciones Unidas/CEPAL.

CEPAL (Comisión Económica para América Latina y el Caribe), 2001. Panorama Social de América Latina y Caribe, 2000-2001. Santiago de Chile: $\mathrm{Na}-$ ciones Unidas/CEPAL.

FOUCAULT, M., 1979. Microfísica do Poder. Rio de Janeiro: Edições Graal.

HAM, C., 1997. Health Care Reform: Learning from International Experiences. Buckingham: Open University Press.

JANOVSKY, K. \& CASSELS, A., 1995. Health policy and systems research: Issues, methods, priorities. In: Health Policy and Systems Development - An Agenda for Research (K. Janovsky, ed.), pp. 11-23, Geneva: World Health Organization.

KNOWLES, J. C. \& LEIGHTON, C., 1997. Measuring Results of Health Sector Reform for System Performance: A Handbook of Indicators. Special Initiative Report 1. Bethesta: ABT Associates Inc./Harvard School of Public Health.

MALLOY, J., 1993. Statecraft, social policy, and governance in Latin America. Governance: An International Journal of Policy and Administration, 6: 220-274.

MATEUCCI, N., 1993. Liberalismo. In: Dicionário de Política (N. Bobbio, N. Matteucci \& G. Pasquino, org.), v. 2, pp. 686-705, 5a Ed. Brasília: Editora Universidade de Brasília.
MELO, M. A., 1998. As sete vidas da agenda pública brasileira. In: Avaliação das Políticas Sociais: Uma Questão em Debate (E. M. Rico, org.), pp. 11-28, São Paulo: Editora Cortez/Instituto de Estudos Especiais, Pontifícia Universidades Católica de São Paulo.

MELO, N. R. \& COSTA, M. A., 1994. Desenvolvimento sustentável, ajuste estrutural e política social: As estratégias da OMS/OPS e do Banco Mundial para a atenção à saúde. Planejamento e Políticas Públicas, 11:50-108.

MOONEY, G. \& JAN, S., 1997. Vertical equity: Weighting outcomes? Or establishing procedures? Health Policy, 39:79-87.

OPPENHEIM, F. E., 1993. Igualdade. In: Dicionário de Política (N. Bobbio, N. Matteucci \& G. Pasquino, org.), v. 2, pp. 597-605, 5a Ed. Brasília: Editora Universidade de Brasília.

OPS (Organización Panamericana de la Salud), 1995. Gasto Nacional y Financiamiento del Sector de la Salud en América Latina y el Caribe: Desafíos para la Década de los Noventa. Washington, DC: OPS/Organización Mundial de la Salud.

OPS (Organización Panamericana de la Salud)/CEPAL (Comisión Económica para América Latina y el Caribe), 1994. Salud, Equidad y Transformación Productiva en América Latina y Caribe. Serie Documentos Reproducidos 41. Washington, DC: OPS.

ROSEN, G., 1980. Da Polícia Médica à Medicina Social - Ensaios sobre a História da Assistência Médica. Rio de Janeiro: Edições Graal.

ROSEN, G., 1994. Uma História da Saúde Pública. São Paulo: Editora Unesp/Editora Hucitec/ABRASCO.

SANTOS, W. G., 1979. Cidadania e Justiça. Rio de Janeiro: Editora Campus.

SANTOS, W. G., 1998. A trágica condição da política social. In: Política Social e Combate à Pobreza (S. H. Abranches, W. G. Santos \& M. A. Coimbra, org.), pp. 33-64, Rio de Janeiro: Jorge Zahar Editor.

SETTEMBRINI, D., 1993. Reformismo. In: Dicionário de Política (N. Bobbio, N. Matteucci \& G. Pasquino, org.), v. 2, pp. 1077-1080, 5a Ed. Brasília: Editora Universidade de Brasília.

SOJO, A., 2001. Reformas de gestión en salud en América Latina. Revista de la Cepal, 74:139-157.

WHITEHEAD, M., 1992. The concepts and principles of equity in health. International Journal of Health Services, 22:429-445.

WHO (World Health Organization), 1995. Achieving Evidence-Based Health Sector Reforms in Sub-Sharan Africa. Brackground Paper for an Inter-Country Meeting. Arusha: WHO.

Recebido em 10 de maio de 2002

Versão final reapresentada em 23 de setembro de 2002 Aprovado em 8 de outubro de 2002 